\title{
Conservação pós-colheita de bacuri (Platonia insignis Mart.) sob refrigeração e embalado em PVC $^{1}$
}

\author{
Maria Alves Fontenele 2 , Raimundo Wilane de Figueiredo ${ }^{3}$, Geraldo Arraes Maia ${ }^{3}$, Ricardo Elesbão Alves ${ }^{4}$ \\ Paulo Henrique Machado de Sousa ${ }^{5}$, Valdomiro Aurélio Barbosa de Souza ${ }^{6}$
}

\begin{abstract}
RESUMO
Nos últimos anos, o bacuri vem se destacando dentre as frutas nativas, de elevado valor socioeconômico, pelas amplas possibilidades de utilização. É amplamente usado pela população amazônica e pode ser encontrado em supermercados de várias cidades. Neste trabalho objetivou-se avaliar o potencial de conservação de frutos do bacurizeiro armazenados em diferentes temperaturas de refrigeração e recobertos com filme de PVC por um período de 36 dias. Houve diminuição dos valores de sólidos solúveis totais, acidez total titulável e açúcares e aumento do pH durante o armazenamento para todas as temperaturas avaliadas, enquanto os valores de clorofila apresentaram grandes variações ao longo do período de armazenamento.
\end{abstract}

Palavra-chave: Bacuri, refrigeração, frutas amazônicas, cloreto de polivinila.

\section{ABSTRACT}

\section{Postharvest conservation of bacuri (Platonia insignis Mart.) packed in PVC and stored under refrigeration}

In the last years, bacuri has stood out among native fruits with socioeconomic value for the great possibilities of utilization. Bacuri is widely used by the Amazon population and can to be found in supermarkets of several cities. The objective of this work was to evaluate the conservation potential of bacuri packed in PVC and stored under different refrigeration temperatures for a period of 36 days. There was a decrease in total soluble solids, titratable acidity and sugars and increase in $\mathrm{pH}$ during storage at all evaluated temperatures, while the chlorophyll content showed great variations over the period of storage.

Key words: Amazonian fruits, bacuri, modified atmosphere, refrigeration.

\footnotetext{
Recebido para publicação em dezembro de 2007 e aprovado em fevereiro de 2010

${ }^{1}$ Parte da dissertação de mestrado apresentada pela primeira autora à UFC. Trabalho financiado pelo Conselho Nacional de Desenvolvimento Científico e Tecnológico - CNPq. ${ }^{2}$ Engenheira de Alimentos, Mestre. Departamento de Tecnologia de Alimentos, Universidade Federal do Ceará, Campus do Pici, Caixa Postal 12168, 60356-000, Fortaleza, Ceará (CE), Brasil. fontenelemalu@gmail.com

${ }^{3}$ Engenheiros-Agrônomos, Doutores. Departamento de Tecnologia de Alimentos, Universidade Federal do Ceará, Campus do Pici, Caixa Postal 12168, 60356-000, Fortaleza, CE, Brasil. figueira@ufc.br, gmaia@secrel.com.br

${ }^{4}$ Engenheiro-Agrônomo, Doutor. Embrapa Agroindústria Tropical. Rua Dra Sara Mesquita, 2270, Planalto do Pici , CEP 60511-110, Fortaleza, CE, Brasil. elesbão@cnpat.br ${ }^{5}$ Químico, Doutor. Departamento de Tecnologia de Alimentos, Universidade Federal do Ceará, Campus do Pici, Caixa Postal: 12168, 60356-000, Fortaleza, CE, Brasil. phenriquemachado@gmail.com

${ }^{6}$ Engenheiro-Agrônomo, Doutor. Embrapa Meio Norte, Av. Duque de Caxias, 5650, Buenos Aires, CEP 64006-220, Terezina, Piauí, Brasil. valdo@cpamn.embrapa.br
} 


\section{INTRODUÇÃO}

O bacuri (Platonia insignis Mart.) é uma fruta nativa da região amazônica do Brasil e Guiana, mas também cresce na Colômbia e no Paraguai (Chitarra \& Chitarra, 2005). No Brasil, o centro de dispersão é o Estado do Pará, podendo também ser encontrado no Maranhão, Mato Grosso, Piauí e Goiás (Ferreira et al., 1987; Silva \& Donato, 1993; Villachica et al., 1996; Aguiar et al., 2008). Como fruta in natura é comercializada, principalmente, nas CEASAs de Belém, São Luís e Teresina, apresentando produção insuficiente para atender à demanda do mercado consumidor dessas capitais. A médio ou longo prazo, essa espécie pode se estabelecer como uma nova e excelente alternativa para os mercados interno e externo de frutas exóticas (Souza et al., 2001).

Segundo o censo agropecuário de 2006 do IBGE (2010), a produção brasileira de bacuri concentra-se nas regiões Norte (33,43\%) e Nordeste (66,23\%), sendo o Maranhão e o Pará os maiores produtores do fruto.

O bacuri é uma baga volumosa, ovóide ou subglobosa, de peso variável entre 200 e 1000 g. A polpa é branco-cremosa, mas passa a amarela quando exposta ao ar. Com odor e sabor agradáveis, engloba, em geral, três sementes, que também são comestíveis (Chitarra \& Chitarra, 2005). De acordo com Teixeira et al. (2005), o bacuri é um fruto não-climatérico. Frutos não-climatéricos só amadurecem quando estiverem ligados à planta. Após a colheita, eles não melhoram suas características sensoriais e nutricionais, embora leve amolecimento e perda de coloração verde possam ocorrer. Podem ser aproveitados como fruta fresca para consumo in natura e para agroindústria de polpa, sorvetes e derivados (Clement \& Venturieri, 1990; Souza et al., 2001). Devido às suas características de odor e sabor, os frutos de bacurizeiro são bastante procurados e consumidos pela população amazônica.

Carvalho et al. (2003) caracterizaram o bacuri, encontrando a seguinte composição média: rendimento percentual de polpa de 27,7\%, 84,35\% de umidade, $15,65 \%$ de sólidos totais, teor de sólidos solúveis totais de 14,53 ${ }^{\circ}$ Brix, pH 3,34, acidez total titulável de 1,24\% e relação ${ }^{\circ}$ Brix/acidez total titulável igual a 11,4, o que levou os autores a concluírem que as características físicas e físico-químicas do bacuri permitem sua utilização tanto para consumo como fruta fresca como na forma industrializada. Segundo Chitarra \& Alves (2001), a refrigeração é o método mais econômico para o armazenamento prolongado de frutas e hortaliças frescas. O uso da refrigeração apresenta uma série de vantagens como manutenção da qualidade do produto, aumento da vida de prateleira, melhor preço, aumento de competitividade no setor, entre outras (Tanabe \& Cortez, 1998).
Chitarra \& Chitarra (2005) afirmaram que a atmosfera modificada é utilizada como complemento da refrigeração no armazenamento. Segundo Jerônimo \& Kanesiro (2000), o uso de atmosfera modificada durante o armazenamento pode reduzir os danos ocasionados pela respiração e pela transpiração, como perda de massa e mudança na aparência. Lana \& Finger (2000) resumiram atmosfera modificada como presença de uma barreira artificial - como embalagem de filme plástico - à difusão de gases em torno do produto, que resulta em redução do nível de $\mathrm{O}_{2}$, aumento do nível de $\mathrm{CO}_{2}$, alteração na concentração de etileno e vapor d’água e alterações em outros compostos voláteis.

Acredita-se que as perdas pós-colheita do bacuri ultrapassem 50\% da produção, em decorrência de processos inadequados de manuseio, transporte e armazenamento (FAO, 2010). Para reduzir essas perdas é preciso entender os processos biológicos e ambientais envolvidos na deterioração após a colheita, e, com base nesses conhecimentos, desenvolver tecnologias que permitam a manutenção da qualidade desses produtos pelo maior tempo possível.

O objetivo foi avaliar o potencial de conservação de frutos do bacurizeiro recobertos com filme de cloreto de polivinila, armazenados em diferentes temperaturas de refrigeração.

\section{MATERIAL E MÉTODOS}

Foram utilizados frutos de bacurizeiro oriundos do Estado do Maranhão, Região Meio Norte do Brasil. Os bacuris, fisiologicamente maduros, foram colhidos na planta e, em seguida, acondicionados em caixas térmicas e transportados, via rodoviária, para a planta de processamento. Os frutos foram selecionados, lavados em água corrente, higienizados (hipoclorito de sódio a $\left.200 \mathrm{mg} . \mathrm{L}^{-1}\right)$. A secagem foi natural e os frutos foram dispostos em bandejas de poliestireno expandido, recobertos com filme de cloreto de polivinila (PVC) tipo 8 , gramatura - $10 \mathrm{mg} / \mathrm{m}^{2}$, armazenados a 7,9 e $11^{\circ} \mathrm{C}(85-$ $90 \%$ UR) e avaliados inicialmente (0 dia) e após 12, 22 e 36 dias de armazenamento.

Foram avaliadas as seguintes características: sólidos solúveis (SS), diluindo $0,5 \mathrm{~g}$ de polpa extraída de três frutos para cada repetição em 2,5 g de água destilada, que após homogeneização e filtragem em papel-filtro foi lido ( ${ }^{\circ}$ Brix) em refratômetro digital, conforme a metodologia recomendada pela AOAC (1995); conteúdo de açúcares solúveis totais, feito com polpa extraída de três frutos para cada repetição, utilizando-se o método da antrona (Yemn \& Willis, 1954), de açúcares redutores, pela técnica do DNS (Miller, 1959) e de clorofila, segundo Engel \& Poggiani (1991). A acidez titulável (AT) foi determinada 
utilizando-se $1 \mathrm{~g}$ de polpa extraída de três frutos para cada repetição, diluída em $50 \mathrm{~mL}$ de água destilada e titulação com $\mathrm{NaOH}$ até pH 8,1, em titulador potenciométrico automático Mettler DL12, com os resultados expressos em percentagem de ácido cítrico (Brasil, 2004); e o pH foi avaliado utilizando-se um potenciômetro (Mettler, modelo DL 12 Titrator) e leitura feita diretamente na polpa (Brasil, 2004).

O experimento foi conduzido segundo o delineamento inteiramente casualizado, em esquema fatorial $3 \times 4$ (temperatura $\mathrm{x}$ tempo), de três repetições (bandejas), com três frutos cada.

Os resultados obtidos foram analisados, estatisticamente, quanto à variância a 5\% de probabilidade e os desdobramentos, submetidos à análise de regressão polinomial. Foram empregados procedimentos do programa estatístico Sisvar 4.3.

\section{RESULTADOS E DISCUSSÃO}

Na análise estatística observou-se que os açúcares redutores apresentaram interações significativas entre os tratamentos ( $\mathrm{p}<0,05)$ e o tempo de armazenamento; enquanto nos parâmetros $\mathrm{pH}$, acidez titulável, sólidos solúveis, açúcares solúveis totais e clorofila total não foram detectadas interações significativas entre os tratamentos e o tempo de armazenamento ( $>0,05)$ (Tabela 1$)$.

Não se verificou interação significativa das diferentes temperaturas de armazenamento com o tempo $(p>0,05)$ sobre os sólidos solúveis totais, os quais variaram em média geral de $14^{\circ} \mathrm{Brix}$ para frutos armazenados a 7 e $9^{\circ} \mathrm{C}$ e $14,6{ }^{\circ}$ Brix para os frutos a $11^{\circ} \mathrm{C}$. Os sólidos solúveis totais foram influenciados somente pelo tempo de armazenamento, verificando-se pequeno decréscimo (Figura 1). Isso pode ser explicado por Huertas et al. (1999) quando afirmaram que a diminuição no teor de SST é um indicativo de que esses estão sendo mais usados na respiração do que produzidos. Os teores de sólidos solúveis totais encontrados foram inferiores aos apresentados por Santos (1988), 19,10 ${ }^{\circ}$ Brix, e próximos aos relatados por Aguiar et al. (2008).

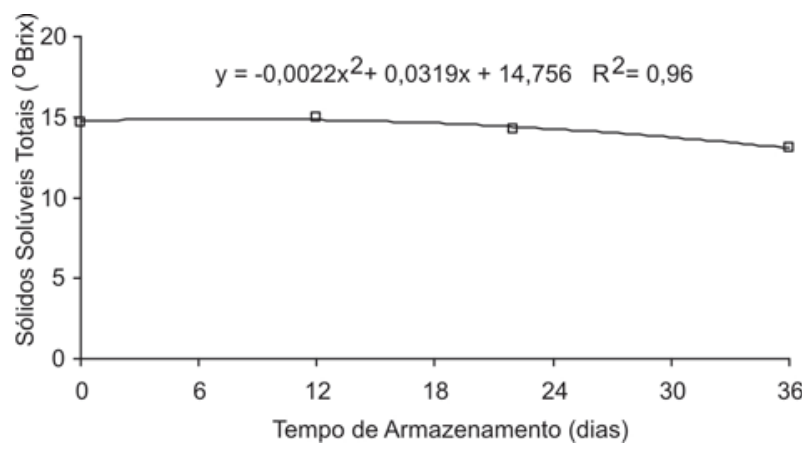

Figura 1. Média dos teores de sólidos solúveis totais ( $\left.{ }^{\circ} \mathrm{Brix}\right)$ de bacuris armazenados sob refrigeração (85-90\% UR), embalados em PVC.

Os açúcares solúveis totais não foram influenciados pelas temperaturas de armazenamento de 7,9 e $11^{\circ} \mathrm{C}$, em que apenas o tempo de armazenamento foi responsável pela variação dos teores desses açúcares. Entretanto, embora o conteúdo desses açúcares tenha apresentado diferença estatística ao longo do armazenamento, verificou-se pequena diferença na média de açúcares ao longo do armazenamento (Figura 2), que provavelmente é resultado de sua utilização como substrato na respiração.

Apesar de valores muito próximos, os frutos armazenados a $11^{\circ} \mathrm{C}$ apresentaram os maiores valores de açúcares solúveis totais, com médias de 7,94\%, e também foram os que menos perderam com o período de armazenamento.

Os açúcares solúveis totais encontrados neste estudo estão de acordo com os valores reportados por Aguiar (2008), de 5,79 a 10,73\%, para bacuris provenientes da Região Meio Norte.

Os frutos que foram mantidos a $7^{\circ} \mathrm{C}$ apresentaram aumento dos açúcares redutores (3,75\%), declinando após 22 dias de armazenamento. Aqueles armazenados a 9 e $11^{\circ} \mathrm{C}$ praticamente mantiveram o teor inicial de açúcares redutores (Figura 3).

O acréscimo no teor de açúcares redutores nos frutos armazenados a $7{ }^{\circ} \mathrm{C}$, provavelmente, pode ser uma resposta à injúria pelo frio. Wang (1990) já reportou o aumento nos conteúdos de açúcares redutores como resposta à injúria pelo frio. A média geral encontrada para açúcares

Tabela 1. Resumo das análises de variâncias para as características de sólidos solúveis totais (SST), açúcares solúveis totais (AST), açúcares redutores (AR), acidez titulável (AT), $\mathrm{pH}$ e clorofila de frutos de bacuri armazenados sob refrigeração $\left(10^{\circ} \mathrm{C}\right)$ e atmosfera modificada

\begin{tabular}{lccccccc}
\hline \multirow{2}{*}{ Fonte de variação } & GL & \multicolumn{7}{c}{ Quadrados Médios } \\
& & SST & AST & AR & AT & pH & Clorofila \\
\hline Temperatura $(\mathrm{T})$ & 2 & $1,1379^{\mathrm{NS}}$ & $0,6938^{\mathrm{NS}}$ & $2,8817^{*}$ & $0,0639^{\mathrm{NS}}$ & $0,0074^{\text {NS }}$ & $16,0808^{\mathrm{NS}}$ \\
Tempo $(\mathrm{t})$ & 3 & $6,2893^{*}$ & $2,3110^{*}$ & $1,6402^{*}$ & $0,5459^{*}$ & $0,0812^{*}$ & $170,8173^{*}$ \\
T x t & 6 & $0,8450^{\mathrm{NS}}$ & $0,6497^{\mathrm{NS}}$ & $1,1272^{*}$ & $0,1890^{\mathrm{NS}}$ & $0,0039^{\mathrm{NS}}$ & $16,1705^{\mathrm{NS}}$ \\
Resíduo & 24 & 0,7863 & 0,5940 & 0,1272 & 0,1552 & 0,0096 & 25,0124 \\
\hline CV $(\%)$ & & 6,22 & 10,06 & 11,21 & 14,70 & 3,26 & 28,30 \\
\hline
\end{tabular}

* F Significativo a 5\%; e NS F não significativo a 5\%.

Rev. Ceres, Viçosa, v. 57, n.3, p. 292-296, mai/jun, 2010 
redutores foi de 3,18\%, valor próximo ao relatado por Moraes et al. (1994), 3,98\%, e Teixeira (2000), 3,64\%.

Para o parâmetro acidez titulável somente o tempo apresentou variação estatístia significativa ( $<<0,05)$, apresentando declínio linear com o tempo de armazenamento (Figura 4). A acidez no início do armazenamento era próxima de 3,00\%, e declinou para 2,70, 2,22 e 2,15\% no final do experimento para as temperaturas de armazenamento de 7,9 e $11^{\circ} \mathrm{C}$, respectivamente. Valores próximos foram reportados por Moraes et al. (1994), e bem inferiores, relatados por Bezerra et al. (2004). Os frutos armazenados a $11^{\circ} \mathrm{C}$ foram os que obtiveram menor média para acidez (2,60\%). Segundo Chitarra \& Chitarra (2005), a acidez decresce em decorrência do processo respiratório e/ou de sua conversão em açúcares, pois os ácidos orgânicos voláteis e não-voláteis estão entre os constituintes celulares mais metabolizados no processo de amadurecimento.

O pH não foi afetado pela temperatura de armazenamento; porém, verificou-se aumento linear estatisticamente significativo com o tempo de armazenamento (Figura 5). Esse pequeno aumento pode ser consequência da diminuição na acidez. Nos armazenamentos a 7 e $9^{\circ} \mathrm{C}$ a média para o $\mathrm{pH}$ foi de 3,25 , e a $11^{\circ} \mathrm{C}, 3,29$; valores próximos aos relatados por Villachica et al. (1996), 3,50, e Bezerra et al. (2004), 3,12.

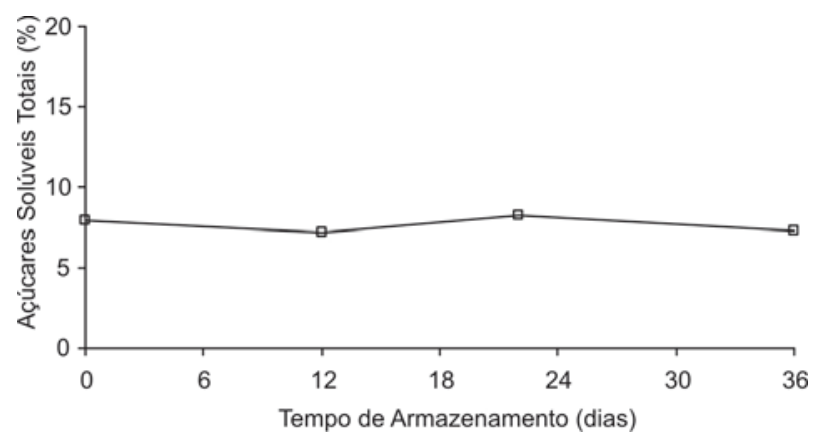

Figura 2. Média dos teores de açúcares solúveis totais (\%) de bacuris armazenados sob refrigeração (85-90\% UR), embalados em PVC.

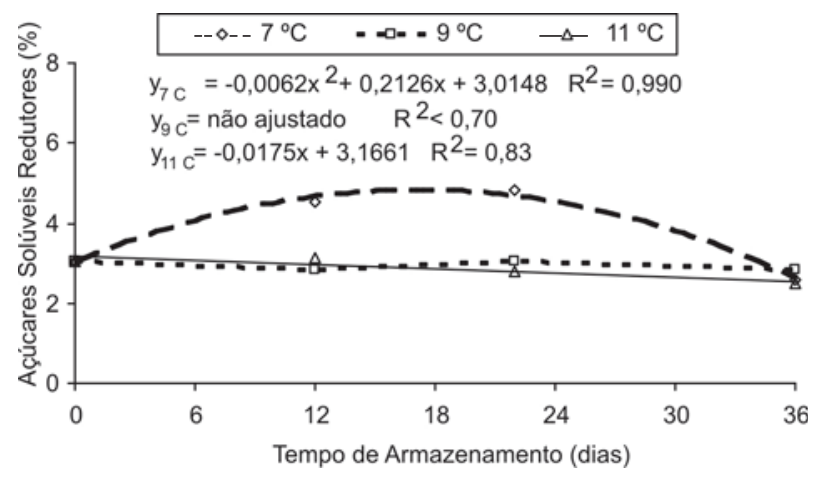

Figura 3. Açúcares solúveis redutores (\%) de bacuris armazenados sob refrigeração (7, 9 e $11{ }^{\circ} \mathrm{C}, 85-90 \%$ UR), embalados em PVC.
O teor de clorofila total teve valor médio de 17,67\% desse pigmento (Figura 6). Os frutos armazenados a $11^{\circ} \mathrm{C}$ apresentaram o menor percentual desse pigmento (16,70\%).

A temperatura de armazenamento não afetou o teor de clorofila total dos frutos de bacuri. Houve efeito significativo do tempo de armazenamento dos frutos no teor de clorofila total $(\mathrm{p}<0,05)$. No entanto, os valores tiveram grandes variações ao longo do período de armazenamento, não podendo serem ajustados a nenhum modelo estatístico (Figura 6), sendo representados somente pela média dos resultados nas três temperaturas estudadas.

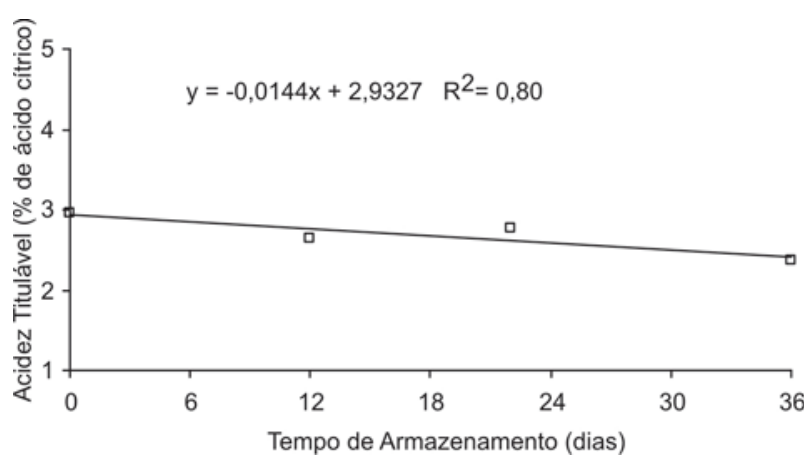

Figura 4. Média dos teores de acidez titulável (\% de ácido cítrico) de bacuris armazenados sob refrigeração (85-90\% UR), embalados em PVC.

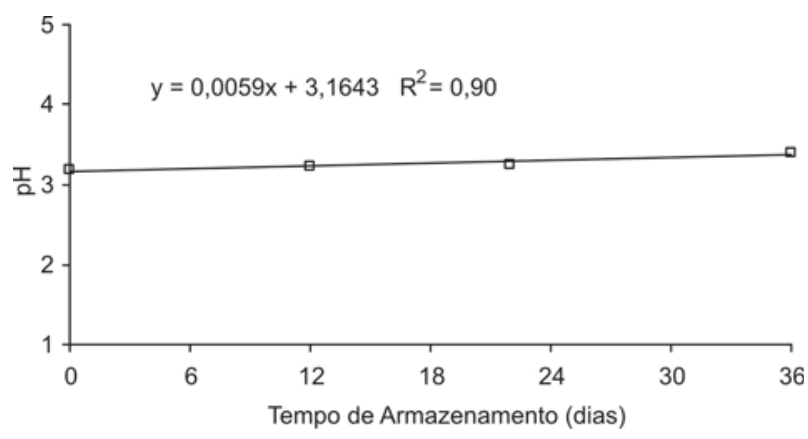

Figura 5. Média dos valores de $\mathrm{pH}$ de bacuris armazenados sob refrigeração (85-90\% UR), embalados em PVC.

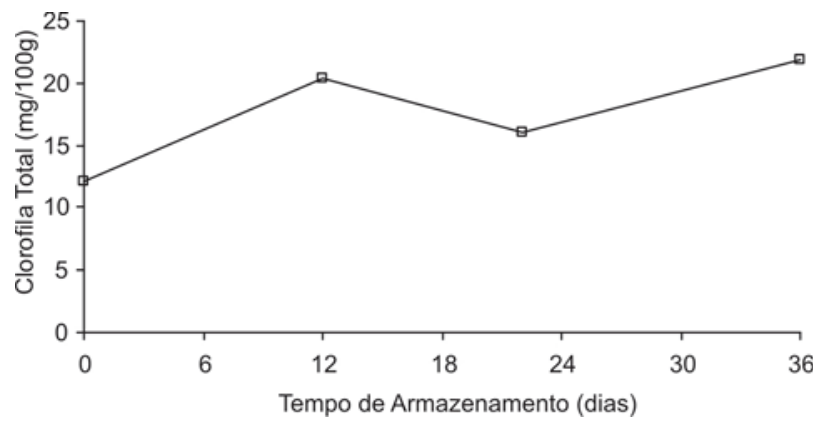

Figura 6. Média dos teores de clorofila total (mg/100g) de bacuris armazenados sob refrigeração (85-90\% UR), embalados em PVC. 


\section{CONCLUSÕES}

A qualidade físico-química dos bacuris não é afetada pelas diferentes temperaturas de armazenamento estudadas.

Os açúcares solúveis totais não são influenciados pelas temperaturas de 7,9 e $11^{\circ} \mathrm{C}$ durante o armazenamento, mas variam com o tempo de armazenamento.

Há redução dos conteúdos de sólidos solúveis totais, acidez total titulável e dos açúcares solúveis totais e aumento do $\mathrm{pH}$ dos bacuris durante os 36 dias de armazenamento sob refrigeração e embalados com filme de PVC.

\section{AGRADECIMENTOS}

À Embrapa Agroindústria Tropical, pelo apoio técnico; à Fundação Cearense de Apoio ao Desenvolvimento Científico e Tecnológico (FUNCAP), pela concessão da bolsa de estudos; e ao Conselho Nacional de Desenvolvimento Científico e Tecnológico (CNPq), pelo apoio financeiro.

\section{REFERÊNCIAS}

Aguiar LP, Figueiredo RW, Alves RE, Maia GA \& Souza VAB de (2008) Caracterização física e físico-química de frutos de diferentes genótipos de bacurizeiro (Platonia insignis Mart.). Ciência e Tecnologia de Alimentos, 28:423-428.

AOAC (1995) Official methods of analysis of the association of analytical chemistry. 16. ed. Arlington, AOAC. 1141p.

Bezerra GAS, Maia GA, Filgueira RW de, Gomes AMM \& Souza Filho M de SM de (2004) Influência da redução da atividade de água, adição de conservantes e braqueamento na preservação da polpa de bacuri por métodos combinados. Boletim CEPPA, 22:217-232.

Brasil (2004) Ministério da Saúde, Agência Nacional de Vigilância Sanitária. Métodos físico-químicos para análise de alimentos, Instituto Adolfo Lutz, 4ª.ed., Brasília, Ministério da Saúde. 1004 p.

Carvalho JEU de, Nazaré RFR de N \& Nascimento MO do (2003) Características físicas e físico-químicas de um tipo de bacuri (Platonia insignis Mart.) com rendimento industrial superior. Revista Brasileira de Fruticultura, 25:326-328.

Chitarra AB \& Alves RE (2001) Tecnologia de pós-colheita para frutas tropicais. Fortaleza, FRUTAL - SINDIFRUTA. 27p.

Chitarra AB \& Chitarra MIF (2005) Pós-colheita de frutos e hortaliças: Glossário. Lavras, UFLA. 256p.

Clement CR \& Venturieri GA (1990) Bacuri e cupuassu. In: Nagy S, Shaw PE \& Wardowiski WG (Eds.) Fruits of tropical and subtropical origin. Composition, properties and uses. Lake Alfred, Florida Department of Citrus, p.178-192.

Engel VL \& Poggiani F (1991) Estudo da concentração de clorofila nas folhas e seus espectros de absorção de luz em função do sombreamento em mudas de quatro espécies florestais. Revista Brasileira de Fisiologia Vegetal, 3:39-45.

FAO (2010) Statistical database. Production and trade. Disponível em: <http://faostat.fao.org/site/339/default.aspx>. Acessado em: 24 de março de 2010.
Ferreira FR, Ferreira SA do N \& Carvalho JEU de (1987) Espécies frutíferas pouco exploradas, com potencial econômico e social para o Brasil. Revista Brasileira de Fruticultura, 9:11-22.

Huertas GGC, Moreno NGN \& Sauri DE (1999) Conservación refrigerada de chicozapote con calentamiento intermitente. Horticultura Mexicana, 7:258.

IBGE. Instituto Brasileiro de Geografia e Estatística (2010) Censo agropecuário 2006. Disponível em: <http:// http:// w w w. s i d r a. i b g e.g o v. b r / b d a / t a b e l a / listabl.asp $\mathrm{z}=\mathrm{t} \& \mathrm{o}=1 \& \mathrm{i}=\mathrm{P} \& \mathrm{e}=\mathrm{l} \& \mathrm{c}=816>$. Acessado em: 24 de março de 2010.

Jerônimo EM \& Kanesiro MAB (2000) Efeito da associação de armazenamento sob refrigeração e atmosfera modificada na qualidade de mangas 'Palmer'. Revista Brasileira de Fruticultura, 22:237-243.

Lana MM \& Finger FL (2000) Atmosfera modificada e controlada: aplicação na conservação de produtos hortícolas. Brasília, Embrapa Comunicação para Transferência de Tecnologia. 34p.

Miller GL (1959) Use of dinitrosalicylic acid reagent for determination of reducing sugars. Analytical Chemistry, 31:426428.

Moraes VH de F, Moraes VH de F, Müller CH, Souza AGC de \& Antônio IC (1994) Native fruit species of economic potential from the Brazilian Amazon. Angewandte Botanik, 68:47-52.

Santos M do SSA (1988) Caracterização física e química do bacuri (Platonia insignis Mart.) e processamento de néctares. Boletim do CEPPA, 6:73-78.

Silva S \& Donato H (1993) Frutas do Brasil. São Paulo, Imprensa de Arte e Projetos e Edições Artísticas. 50p.

Souza VAB, Araújo ECE, Vasconcelos LFL \& Lima OS da C (2001) Variabilidade de características físicas e químicas de frutos de germoplasma de bacuri da Região Meio-Norte do Brasil. Revista Brasileira de Fruticultura, 23:677-683.

Tanabe CS \& Cortez LAB (1998) Aumento da competitividade no setor de frutas e hortaliças com a implantação da "cadeia do frio” no Brasil. In: Simpósio Avanços Tecnológicos na Agroindústria Tropical, Fortaleza. Anais, EMBRAPA/CNPAT. p.229-232.

Teixeira GH de A, Durigan JF, Lima MA, Alves RE \& Filgueiras HAC (2005) Postharvest changes and respiratory pattern of bacuri fruit (Platonia insignis Mart.) at different maturity stages during ambient storage. Acta Amazônica, 35:17-21.

Teixeira GH de A (2000) Frutos do bacurizeiro (Platonia insignis Mart.): Caracterização, qualidade e conservação. Dissertação de Mestrado, Universidade Estadual Paulista Júlio de Mesquita Filho, São Paulo, 106p.

Villachica H, Carvalho JEU de, Müller CH, Diaz SC \& Almanza M (1996) Frutales y hortaliças promossoras de la Amazônia. Lima, Tratado de Cooperación Amazônica. Secretaria Pró-Tempore. p.152-156 (Publicaciones, 44).

Wang CY (1990) Chilling injury of horticultural crops. Florida, CRC Press. 300p.

Yemn EW \& Willis AJ (1954) The estimation of carbohydrate in plant extracts by anthrone. The Biochemical Journal, 57:508514 .

Rev. Ceres, Viçosa, v. 57, n.3, p. 292-296, mai/jun, 2010 